\title{
Energy Conservation Effect of Refrigerated Cabinets at Supermarket Utilizing the Exhaust Heat from Dispersed Power
}

\author{
Tatsuya Shikano ${ }^{1}$, Sang-Chul Bae ${ }^{2}$, Masafumi Katsuta ${ }^{1}$ and Tomohiro Anamizu ${ }^{1}$ \\ 1. Department of Modern Mechanical Engineering, Waseda University, Tokyo 169-0072, Japan \\ 2. Environmental Research Institute, Waseda University, Saitama 367-0035, Japan
}

Received: December 21, 2014 / Accepted: February 02, 2015 / Published: April 30, 2015.

\begin{abstract}
Since the nuclear disaster occurred from huge earthquake in Japan 2011, Japanese energy generation system has been expected to prioritize safety and trustworthiness. To meet this requirement, distributed power supply systems are considered to be one of solutions. In this study, we aimed to conserve energy and reduce carbon dioxide emission of supermarket which installed a novel environment-friendly dispersed power. We focused the energy used by refrigerated cabinets. We built small scale model of supermarket which was equipped with dispersed power. From this scale model, the energy conservation effect of supercooling is from $10 \%$ to $25 \%$ during the summertime and intermediate time. At last, we found that when outside temperature is about $14{ }^{\circ} \mathrm{C}$ or more, supercooling was effective. In addition, since energy consumption of refrigerated cabinet is influenced by inside enthalpy, we controlled the inside air temperature and humidity by installing desiccant system and examined its effect.
\end{abstract}

Key words: Dispersed power, energy conservation, supermarket, refrigerated cabinets, supercooling.

\section{Introduction}

Since the nuclear disaster was caused by the Great East Japan Earthquake in 2011, Japanese energy generation system has been expected to prioritize safety and trustworthiness. Majority of power supply is depending on thermal power generation by fossil fuel because all nuclear power plants are out of operation [1]. Taking into account, environmental issues such as global warming, energy saving strategy are very important. In Japanese industry, consumer sector's energy consumption increased 2.4 times from the 1970s and supermarkets consume the most energy in consumer sector [2]. To reduce the power consumption of supermarkets, many kinds of methods had been introduced all over Japan. For example, rearrange commodities to reduce thermal load, clean cold air

Corresponding author: Sang-Chul Bae, visiting associate professor, research fields: heat transfer engineering and thermodynamics. E-mail: scbae@aoni.waseda.jp. outlet and turn off extra illumination [3]. Though these methods are easy to do, large energy saving effect can not be expected. It needs mechanical method in order to reduce more power consumption. Therefore, it is considered that, it is important to install EMS (energy management system) into the supermarket [4].

From these backgrounds mentioned above, 1/15 scale model store which installed a novel environment-friendly dispersed power was built and EMS which controls not only electricity but also exhaust heat was developed. To reconstruct supermarket at this model store, we measured the power consumption of devices which is in the real supermarket and thermal environment. This supermarket is located in Isesaki City, the northern Kanto region. From this measurement, the power consumption of refrigerated cabinet accounted for more than $60 \%$ of that of all electric systems. In addition, it accounted for $85 \%$ during the summer [5]. Therefore, our interests focused on the power 
consumption of refrigerated cabinets and it is expected that reducing the power consumption of the refrigerated cabinet by condenser outlet supercooling has large energy saving effect. Actually, it was confirmed the power consumption can be reduced by $10 \%$ using supercooling with ice storage [6].

\section{1/15 Scale Model Store Data}

\subsection{The Information about Store Model}

To investigate the effect of supercooling, 1/15 scale model store was used. The main apparatus in store model and its schematic diagram are shown in Fig. 1. This store set up gas engine whose output power is $9.9 \mathrm{~kW}$. This gas engine generates electricity and makes exhaust heat at $80{ }^{\circ} \mathrm{C}$. Adsorption refrigerator can make $7{ }^{\circ} \mathrm{C}$ cold water and desiccant material (absorbent) is regenerated by using this exhaust heat. Hot and cold water are used in many ways at this model store. In addition, this store has solar panels and solar thermal collectors for reducing $\mathrm{CO}_{2}$. PCM (thermal storage system with phase change materials) can maintain the temperature of cold water with $7{ }^{\circ} \mathrm{C}$. Heat pump air conditioner and desiccant system were used to make the model store's thermal environment. Specifications of four apparatuses are shown in Table 1.

\subsection{Fundamental Experiment}

We did fundamental experiment to find out which kind of parameter affects the power consumption of refrigerated cabinet. Without modification to the refrigerated cabinet cycle, we run the refrigerated cabinet all day long on May 30th. We measured inside and outside thermal environment and the power consumption of the refrigerated cabinet every $5 \mathrm{~min}$.

Fig. 2 shows two kinds of parameters which affect the power consumption. In Fig. 2, the change pattern

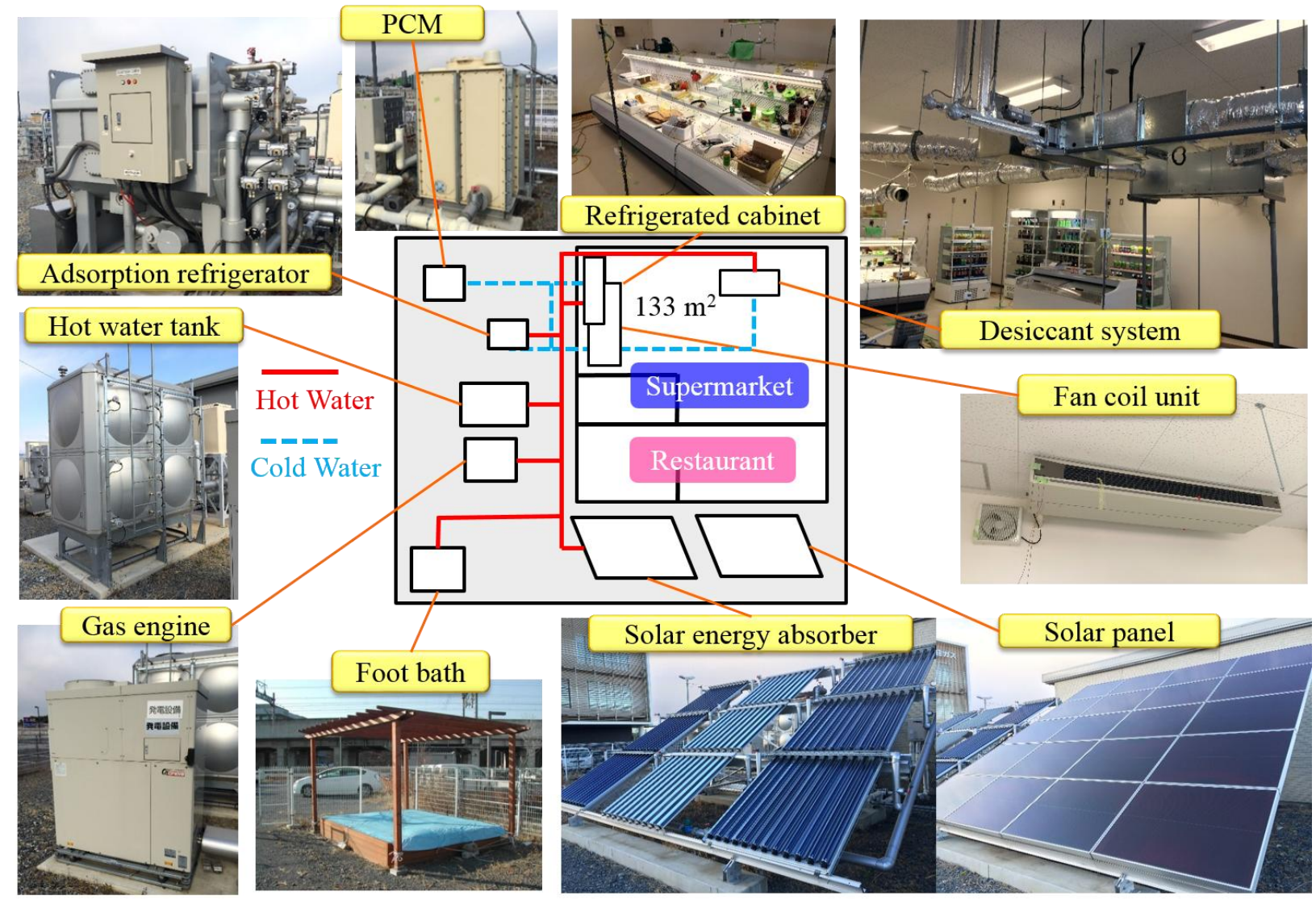

Fig. 1 All system of 1/15 model store. 
Table 1 Specifications of apparatuses in model store.

(a) Gas engine

\begin{tabular}{|c|c|c|}
\hline \multicolumn{2}{|c|}{ Manufacture } & Yanmar \\
\hline \multicolumn{2}{|l|}{ Model } & CP10VB1-SNB \\
\hline \multicolumn{2}{|c|}{ Output power } & $9.9 \mathrm{~kW}$ \\
\hline \multicolumn{2}{|c|}{ Electric voltage } & $100 \mathrm{~V}$ \\
\hline \multicolumn{2}{|l|}{ Fuel } & City Gas 12 A \\
\hline \multicolumn{2}{|l|}{ Hot water } & $65^{\circ} \mathrm{C} \rightarrow 70^{\circ} \mathrm{C}\left(\operatorname{Max} 79^{\circ} \mathrm{C}\right)$ \\
\hline \multicolumn{2}{|l|}{ Flow rate } & $48.2 \mathrm{~L} / \mathrm{min}$ \\
\hline \multicolumn{2}{|c|}{ Heat recovery rate } & $53.3 \%$ \\
\hline \multicolumn{3}{|c|}{ (b) Adsorption refrigerator } \\
\hline \multicolumn{2}{|c|}{ Manufacture } & Mayekawa \\
\hline \multicolumn{2}{|l|}{ Model } & ADR-Z2012 \\
\hline \multicolumn{2}{|l|}{ Refrigerant } & $\mathrm{H}_{2} \mathrm{O}$ \\
\hline \multicolumn{2}{|c|}{ Adsorbent material } & Zeolite \\
\hline \multirow{2}{*}{ Hot water } & Temperature & $75^{\circ} \mathrm{C} \rightarrow 67.8^{\circ} \mathrm{C}$ \\
\hline & Flow rate & $60 \mathrm{~L} / \mathrm{min}$ \\
\hline \multirow{2}{*}{ Cold water } & Temperature & $13^{\circ} \mathrm{C} \rightarrow 7^{\circ} \mathrm{C}$ \\
\hline & Flow rate & $43.3 \mathrm{~L} / \mathrm{min}$ \\
\hline
\end{tabular}

(c) Desiccant system

\begin{tabular}{|c|c|c|c|}
\hline Manufacture & \multicolumn{3}{|c|}{ Mitsubishi plastics } \\
\hline Model & \multicolumn{3}{|c|}{ AQSOAE-0320H201-UW00 } \\
\hline Absorbent Material & \multicolumn{3}{|c|}{ Zeolite } \\
\hline Regeneration & \multicolumn{3}{|c|}{$60^{\circ} \mathrm{C}$} \\
\hline & \multicolumn{2}{|c|}{ Before processing } & After processing \\
\hline Air volume & \multicolumn{2}{|c|}{$241 \mathrm{~m}^{3} / \mathrm{h}$} & $240 \mathrm{~m}^{3} / \mathrm{h}$ \\
\hline Air temperature & \multicolumn{2}{|c|}{$25^{\circ} \mathrm{C}$} & $44^{\circ} \mathrm{C}$ \\
\hline Relative humidity & \multicolumn{2}{|c|}{$60 \%$} & $13.9 \%$ \\
\hline Absolute humidity & \multicolumn{2}{|c|}{$11.89 \mathrm{~g} / \mathrm{kg}$} & $7.89 \mathrm{~g} / \mathrm{kg}$ \\
\hline \multicolumn{4}{|c|}{ (d) Refrigerated cabinet } \\
\hline \multicolumn{2}{|l|}{ Manufacture } & \multicolumn{2}{|l|}{ Panasonic } \\
\hline \multicolumn{2}{|l|}{ Model (cabinet) } & \multicolumn{2}{|c|}{ CPS-EX2065 } \\
\hline \multicolumn{2}{|c|}{ Model (condensing unit) } & \multicolumn{2}{|c|}{ OCU-NR200F } \\
\hline \multicolumn{2}{|c|}{ Refrigerant } & \multicolumn{2}{|c|}{$\mathrm{R} 404 \mathrm{a}$} \\
\hline \multicolumn{2}{|c|}{ Temperature setting } & \multicolumn{2}{|l|}{$4^{\circ} \mathrm{C}$} \\
\hline \multicolumn{2}{|c|}{ Evaporating temperature } & \multicolumn{2}{|l|}{$-10^{\circ} \mathrm{C}$} \\
\hline \multicolumn{2}{|c|}{ Power consumption } & \multicolumn{2}{|l|}{$1.91 \mathrm{~kW}$} \\
\hline
\end{tabular}

of power consumption resembles that of outside air temperature closely. The change pattern of inside air enthalpy is almost the same as that of energy consumption. Thus, the result of this verification, the power consumption highly depended on the inside air enthalpy and the outside air temperature. In order to reduce the influence of outside air temperature, we installed the system which carries out supercooling, and checked the effect. And, in order to check the

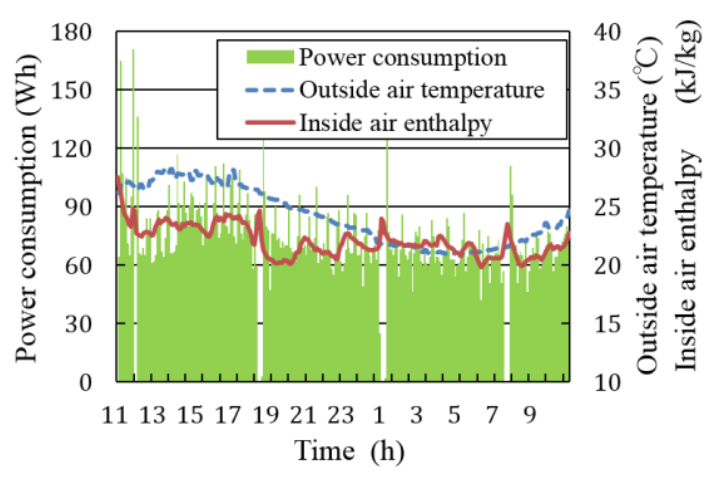

Fig. 2 Result of fundamental experiment.

energy conservation effect of inside humidity control, the desiccant system is installed.

\subsection{Supercooling Experiment}

Experimental apparatus of supercooling experiment and $p$ - $h$ diagram are shown in Fig. 3.

As shown in Fig. 3a, the basic refrigeration cycle that consists of four kinds of components (compressor, condenser, expansion valve, and evaporator) is used. To investigate the effect of supercooling, a heat exchanger 4 was installed after condenser 2. Cold water for supercooling is supplied by adsorption refrigerator using exhaust heat of gas engine. We can choose with and without supercooling condition by manipulating the valves 3 and 3'.

As shown in Fig. 3b, the effect of supercooling can be examined by next equation. Without supercooling, COP (coefficient of performance) can be defined by using Eq. (1):

$$
\mathrm{COP}=\left(h_{1}-h_{4}\right) /\left(h_{2}-h_{1}\right)
$$

On the other hand, the COP with supercooling can be defined by using Eq. (2):

$$
\mathrm{COP}=\left(h_{1}-h_{4}{ }^{\prime}\right) /\left(h_{2}-h_{1}\right)
$$

COP can be improve by supercooling effect, because the numerator of Eq. (2), which is refrigerating effect, became $\left(h_{1}-h_{4}\right.$ ') higher than that of Eq. (1). The cooling capacity also should be increased by supercooling.

\subsection{Energy Conservation by Dehumidification}

According to the fundamental experiment, it was 


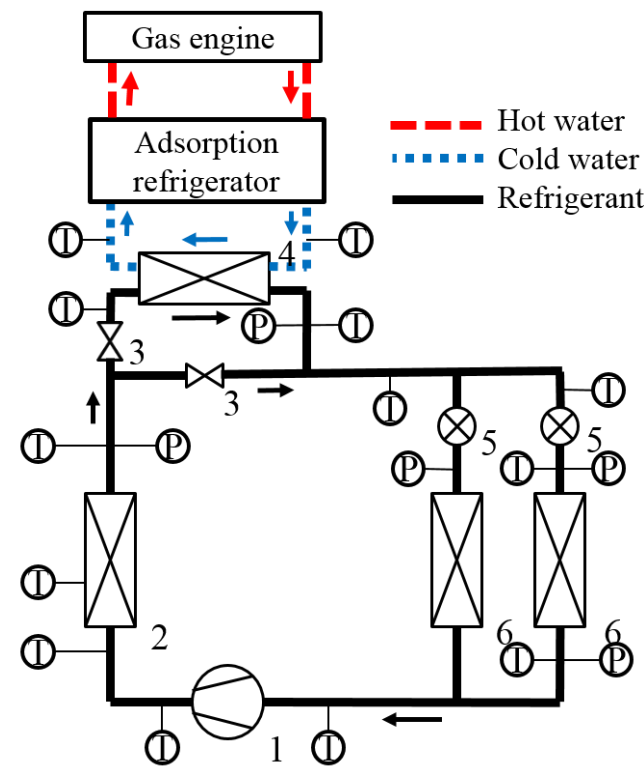

(a) Experimental apparatus

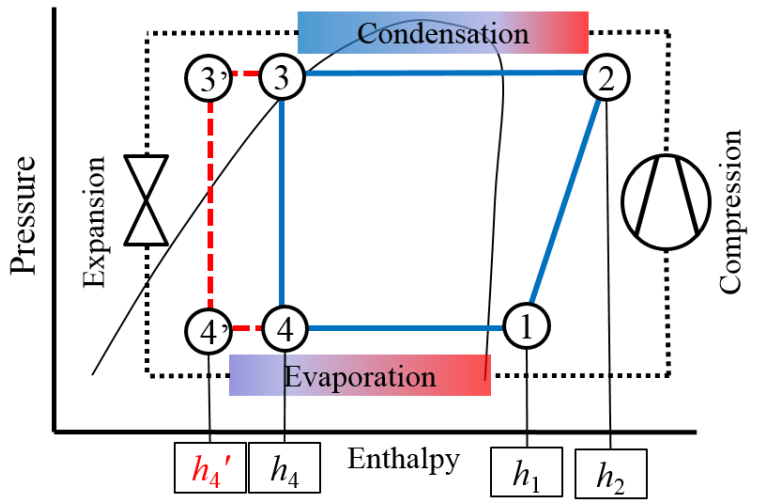

(b) p-h diagram

Fig. 3 Supercooling experiment: 1-compressor; 2-condenser; 3, 3'-valve; 4-heat exchanger; 5-expansion valve; 6-evaporator (refrigerant: R404A).

verified that the power consumption of the refrigerated cabinet highly depended on the inside air enthalpy. In Japan, during May to August, it is very humid season as shown in Fig. 4. The air conditioning load can be reduced by controlling humidity [7]. It is also effective for the refrigerated cabinets because the cooling load of the cabinets is mostly from the inlet air [8]. Thus, if we dehumidify inside air, it seems to be able to reduce the power consumption of the refrigerated cabinet. To dehumidify the inside air, we installed the desiccant system whose desiccant is regenerated by exhaust heat. And, supply air is cooled by cooling water which was made from adsorption refrigerator.

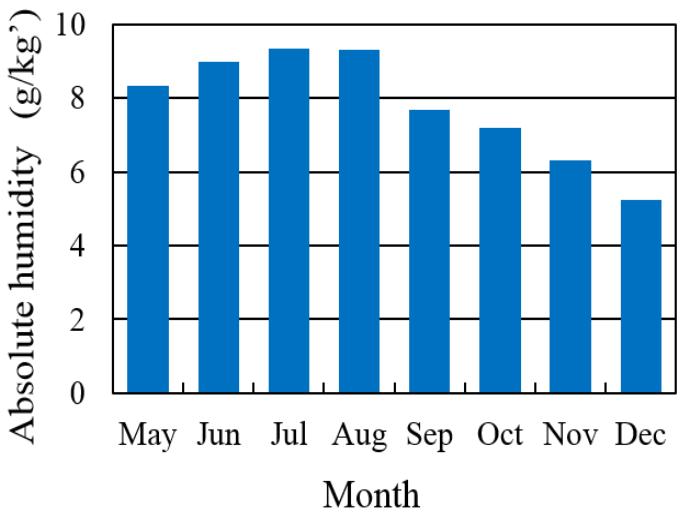

Fig. 4 Monthly inside air absolute humidity of model store (at Honjo).

Table 2 Thermal environment.

\begin{tabular}{lll}
\hline & $\begin{array}{l}\text { Thermal } \\
\text { environment 1 } \\
\text { (HP air } \\
\text { conditioner) }\end{array}$ & $\begin{array}{l}\text { Thermal } \\
\text { environment 2 } \\
\text { (desiccant air } \\
\text { conditioner) }\end{array}$ \\
\hline Temperature $\left({ }^{\circ} \mathrm{C}\right)$ & 25 & 28 \\
Relative humidity $(\%)$ & 50 & 40 \\
\hline
\end{tabular}

Desiccant system experiment had been done in August. The thermal environment of model store is shown in Table 2. We prepared two kinds of conditions. Thermal environment condition 1 is the target condition at the time of HP (heat pump) air conditioner use. And, the thermal environment condition 2 is the target condition at the time of desiccant system use. We determine the temperature of thermal environment condition 2 is a little higher than that of usual, because people can feel comfortable at low relative humidity condition.

\subsection{Experimental Methodology}

We began to measure inside and outside thermal environment and many kinds of state points about the refrigerated cabinet from July. According to fundamental experiment, we could know the outside air temperature and inside air enthalpy had effects to the power consumption of the refrigerated cabinet. Then we analyzed these data by seasonal, summer, autumn and winter, because temperature and humidity changed rapidly in one year. Table 3 shows the detail conditions of measurement. 
Table 3 Detail conditions of measurement.

\begin{tabular}{ll|l}
\hline Operating time & 10:00 a.m.-18:00 p.m. \\
\hline Period & $\begin{array}{l}\text { Summer: Jul.-Aug. } \\
\text { Autumn: Sep.-Oct. } \\
\text { Winter: Nov.-Dec. }\end{array}$ \\
\hline \multirow{2}{*}{ Objectives } & $\begin{array}{l}\text { Refrigerated } \\
\text { cabinet }\end{array}$ & $\begin{array}{l}\text { Pressure } \\
\text { temperature }\end{array}$ \\
\cline { 2 - 3 } & $\begin{array}{l}\text { Thermal } \\
\text { environment }\end{array}$ & $\begin{array}{l}\text { Inside air temperature and } \\
\text { relative humidity } \\
\text { outside air temperature } \\
\text { and relative humidity }\end{array}$ \\
\hline Measurement items & $\begin{array}{l}\text { Logging each moment value for every 5 } \\
\text { min }\end{array}$ \\
\hline
\end{tabular}

\section{Results and Discussion}

\subsection{The Influence of the Outside Air Temperature}

The influence of the outside air temperature on condensation pressure and power consumption is shown in Fig. 5, and each plot shows significant data at every hour. The condensation pressure with outside air temperature is shown in Fig. 5a. The condensation pressure was affected by the outside air temperature regardless of supercooling. The power consumption of the compressor is increased with increasing condensation pressure. Therefore, it was recognized that the power consumption was directly correlated to the outside air temperature as shown in Fig. 5b.

\subsection{The Results of the Supercooling}

In Fig. 6, it shows the power consumption results with and without supercooling experiments of each season.

In every season, certain two days which had had similar outside thermal environment conditions were chosen and compared. Table 4 shows energy conservation effects and thermal environment conditions in each season.

By supercooling, the power consumption of the refrigerated cabinet was reduced more than $25 \%$ in summer time. On the other hand, the reduction rate in autumn was $15 \%$ and in winter was only $6 \%$. It was found that the largest supercooling effect was obtained in summer. Thus, it was considered that the outside air temperature is related to the effect of supercooling. In

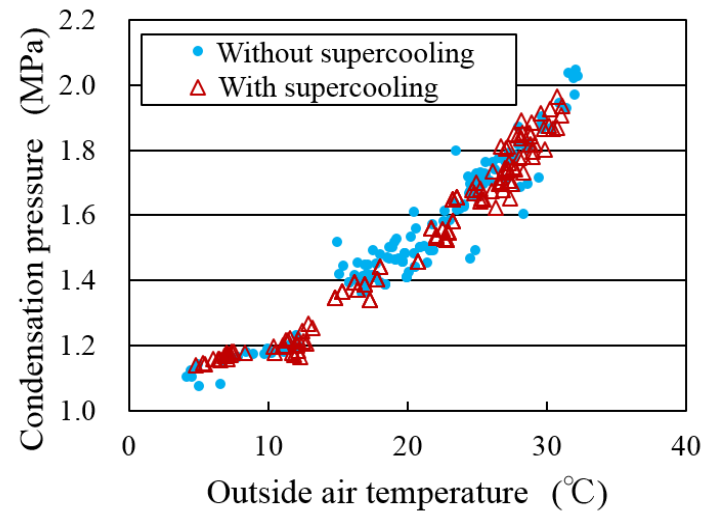

(a) Condensation pressure

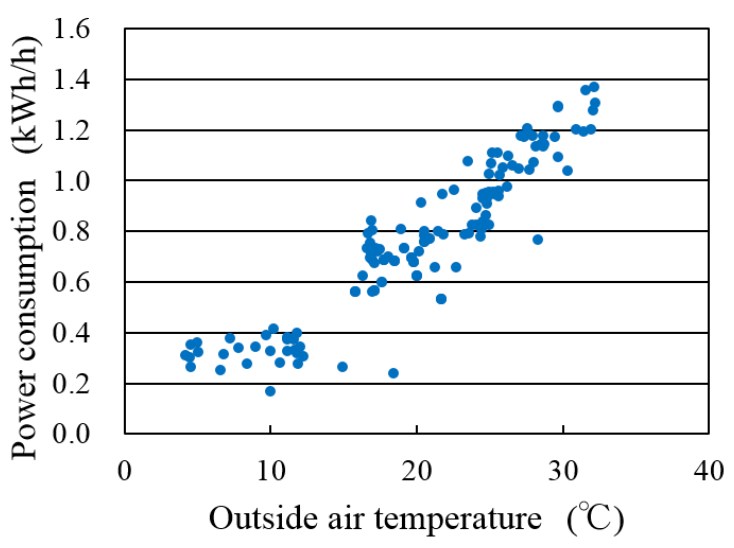

(b) Power consumption

Fig. 5 Relationship between condensation pressure and power consumption to outside air temperature.

order to analyze these results, the relations between power consumption of the refrigerated cabinet and outside air temperature were shown in Fig. 7. The plots should be categorized with and without supercooling and approximate line was calculated by least-squares method, then the point of intersection became $14{ }^{\circ} \mathrm{C}$.

As shown in Fig. 7, there was not so much difference in power consumption of both on outside air conditions lower than $14{ }^{\circ} \mathrm{C}$. However, when the outside temperature became $14{ }^{\circ} \mathrm{C}$ or more, a significant difference appeared. According to the rise of outside air temperature, the supercooling effect also becomes large.

\subsection{Results of Desiccant System Experiment}

The power consumption of the refrigerated cabinet 


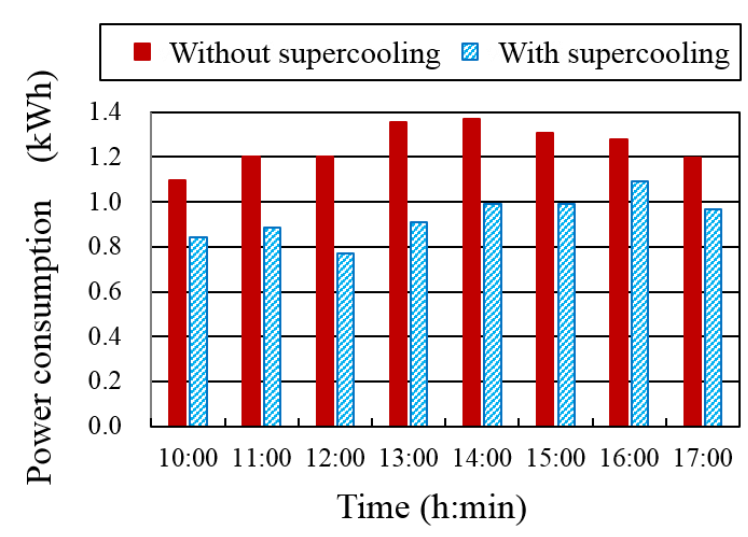

(a) Summer

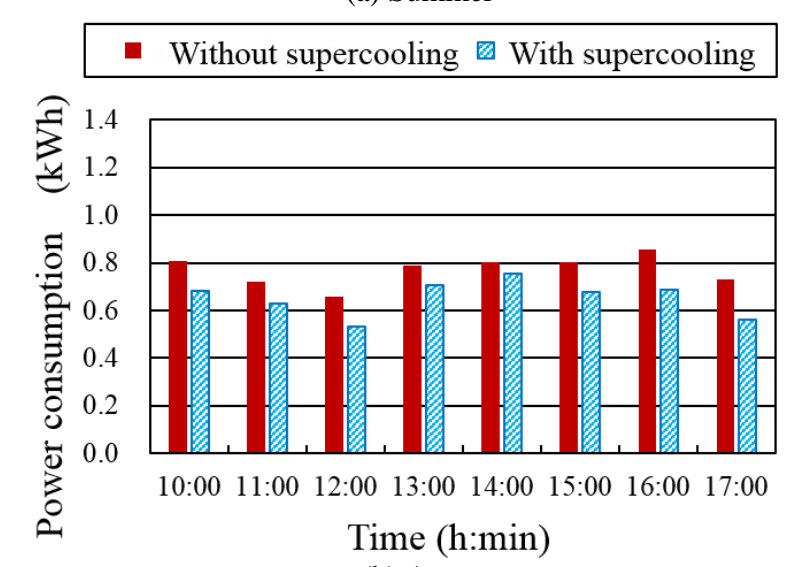

(b) Autumn

- Without supercooling With supercooling

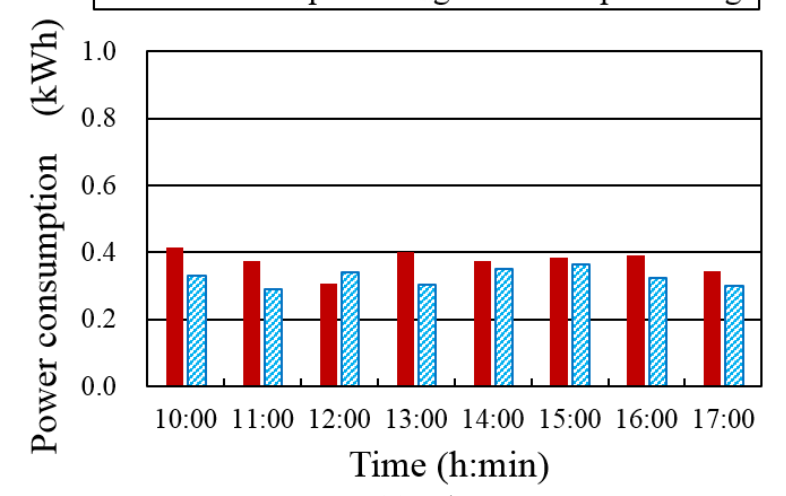

(c) Winter

Fig. 6 The results of supercooling effect of each season. is highly depended on the indoor air enthalpy. However, generally the indoor air temperature was maintained at target temperature throughout the year. That is the reason why our interest focused on the relation between absolute humidity and the power consumption of the refrigerated cabinet. Because we did not have the device that controls the outside thermal environment conditions, these experiments were carried out under almost the same outside thermal environment condition.

From Fig. 8a, the power consumption was directly proportional to the inside air absolute humidity and it was confirmed that dehumidification is very effective for energy saving. The plots in Fig. 8a show the power consumption of the refrigerated cabinet at every hour and these data were taken at the outside temperature $20{ }^{\circ} \mathrm{C}$ in autumn. Fig. 8b shows the result of energy consumption by desiccant system and the daily amount of power consumption of the refrigerated cabinet. This experiment was achieved on July 30th and Aug. 03, 2013 because the outside air enthalpy of these days was almost same. According to Fig. 8b, the power consumption of the refrigerated cabinet was reduced about $11 \%$ in the daytime. By the Building Standards Act, the relative humidity in the buildings should be kept at $40 \%$ or over. The temperature of our supermarket is set at about $23{ }^{\circ} \mathrm{C}$ through the year. When the thermal condition in the room is $23{ }^{\circ} \mathrm{C}$ and $40 \% \mathrm{RH}$, absolute humidity is about $7 \mathrm{~g} / \mathrm{kg}$ ' Therefore, when the absolute humidity in the daytime is more than $7 \mathrm{~g} / \mathrm{kg}$, it is identified that, the energy saving with using desiccant system is very effective. As shown in Fig. 4, because the average absolute

Table 4 Experimental conditions and supercooling effect.

\begin{tabular}{lllllll}
\hline & Supercooling & Date & $\begin{array}{l}\text { Outside air temperature } \\
\left({ }^{\circ} \mathrm{C}\right)\end{array}$ & $\begin{array}{l}\text { Inside enthalpy } \\
(\mathrm{kJ} / \mathrm{kg})\end{array}$ & $\begin{array}{l}\text { Degree of supercooling } \\
\left({ }^{\circ} \mathrm{C}\right)\end{array}$ & $\begin{array}{l}\text { Reduction rate } \\
(\%)\end{array}$ \\
\hline \multirow{2}{*}{ Summer } & - & Jul. 30 & 31 & 51 & 1.7 & 25.6 \\
& $\circ$ & Jul. 31 & 30 & 48 & 27.9 & \\
\multirow{2}{*}{ Autumn } & - & Oct. 17 & 20 & 41 & 1.6 & 15.1 \\
& - & Nov. 01 & 19 & 41 & 15.1 & \\
\multirow{2}{*}{ Winter } & - & Nov. 17 & 11 & 36 & 0.2 & 6.3 \\
\hline
\end{tabular}

(०: use, - : nonuse). 


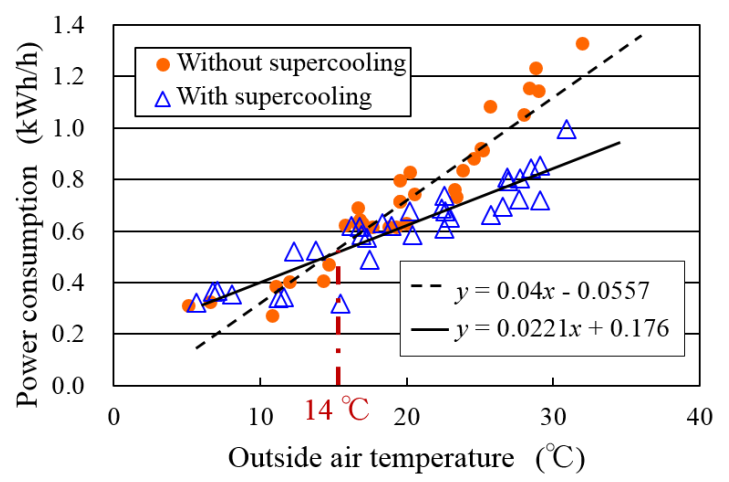

Fig. 7 The effect of supercooling.

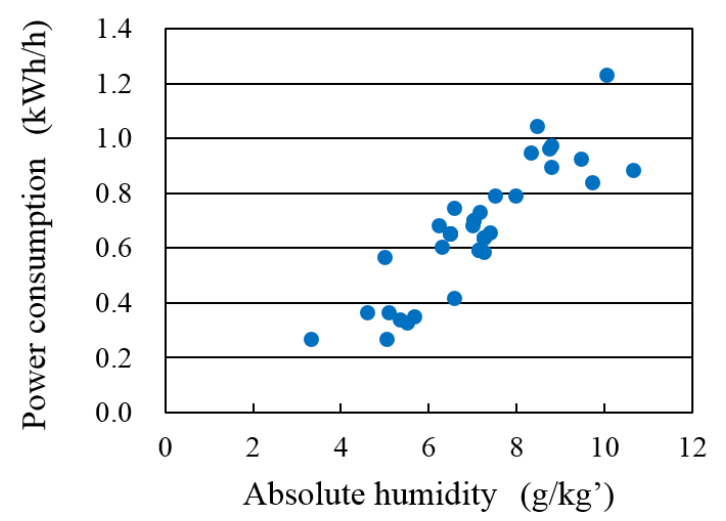

(a) Influence of humidity

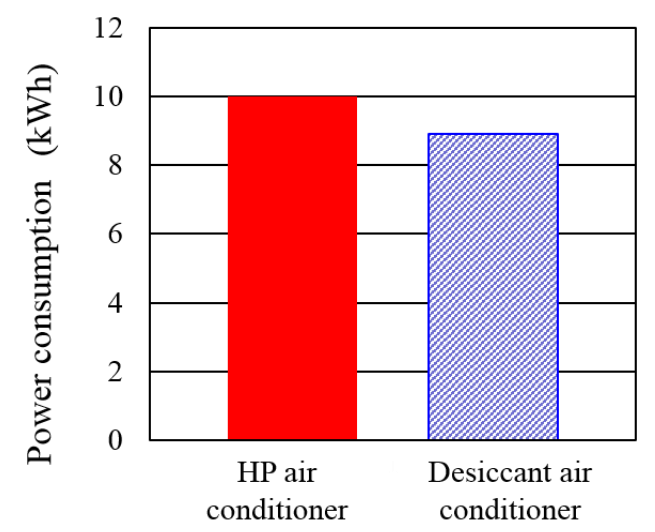

(b) Energy conservation by dehumidification

Fig. 8 Influence of dehumidification 。

humidity from May to August is $7 \mathrm{~g} / \mathrm{kg}$ ' or more. Using desiccant system can achieve large energy saving effect.

\subsection{The Reduction of $\mathrm{CO}_{2}$ Emission}

The decrease amount of refrigerated cabinet's power consumption by supercooling and dehumidification using desiccant system was clarified.
Then the reduction of $\mathrm{CO}_{2}$ emission is discussed in the following section. The apparatuses shown in Table 5 were included in the calculation of $\mathrm{CO}_{2}$ emission in this experiment.

And also the specific energy consumption in model store was made the same with that of real store by using the floor are. The seasonal specific energy consumptions of model store and real store were shown in Table 6. In order to calculate the specific energy consumption, we used refrigerated cabinet's power consumption which does not use supercooling.

Basically, the apparatuses in model store used the electricity made by gas engine except for the apparatuses using $200 \mathrm{~V}$ power source such as pump, adsorption refrigerator and refrigerated cabinet used that of grid power. That is, two types of emission coefficient were needed. We used $0.55 \mathrm{~kg}\left(\mathrm{CO}_{2}\right) / \mathrm{kWh}$ for grid power and $0.63 \mathrm{~kg}\left(\mathrm{CO}_{2}\right) / \mathrm{kWh}$ for gas engine to calculate. The $\mathrm{CO}_{2}$ emission of supercooling experiment discussed in Section 3.2 is shown in Table 7.

From Table 7, $\mathrm{CO}_{2}$ emission of supercooling experiment was higher than that of without supercooling experiment in all season, because the power consumption of adsorption refrigerator was higher than the reduction of refrigerated cabinet's power consumption. Namely, the $\mathrm{CO}_{2}$ reduction by applying supercooling is not effective because amount of $\mathrm{CO}_{2}$ emission from adsorption refrigerator is large. If, however, there are more ways to use cold heat from adsorption refrigerator such as fan coil unit, supercooling can be one of effective measures. Taking into account not only supercooling effect but also air conditioner, Table 8 shows the comparison of $\mathrm{CO}_{2}$ emission between operating with or without exhaust heat. We obtained this data at summertime when the outside air temperature was $31{ }^{\circ} \mathrm{C}$ and preset temperature of fan coil unit was the same as HP (heat pump) air conditioner.

Therefore, it enables us to reduce nearly $13 \mathrm{~kg} \mathrm{CO}_{2}$ emissions at supermarket by utilizing exhaust heat, 
Table 5 Apparatuses used by experiment.

\begin{tabular}{|c|c|c|c|c|c|}
\hline \multirow{2}{*}{\multicolumn{2}{|c|}{ Apparatus }} & \multicolumn{2}{|c|}{ Supercooling experiment } & \multicolumn{2}{|c|}{ Dehumidification experiment } \\
\hline & & $\begin{array}{l}\text { Without } \\
\text { supercooling }\end{array}$ & With supercooling & HP air conditioner & $\begin{array}{l}\text { Desiccant air } \\
\text { conditioner }\end{array}$ \\
\hline \multicolumn{2}{|c|}{ Refrigerated cabinet } & o & o & 0 & $\circ$ \\
\hline \multicolumn{2}{|l|}{ Supercooling } & - & ○ & - & - \\
\hline \multirow{2}{*}{$\begin{array}{l}\text { Refrigeration } \\
\text { apparatus }\end{array}$} & Adsorption refrigerator & - & ० & - & o \\
\hline & Cooling tower & - & o & - & ○ \\
\hline \multicolumn{2}{|c|}{ HP air conditioner } & - & - & $\circ$ & o \\
\hline \multicolumn{2}{|c|}{ Desiccant air conditioner } & - & - & - & ○ \\
\hline \multicolumn{2}{|c|}{ Pump } & - & ० & ○ & ○ \\
\hline
\end{tabular}

Table 6 Specific energy consumption.

\begin{tabular}{lllll}
\hline & $\begin{array}{l}\text { Floor area } \\
\end{array}$ & \multicolumn{2}{c}{ Specific energy consumption $\left(\mathrm{kWh} / \mathrm{m}^{2}\right)$} \\
\cline { 2 - 5 } & Summer & 0.63 & Intermediate season & Winter \\
\hline Real store & 2754 & 0.13 & 0.37 & 0.33 \\
Model store & 77.7 & 0.08 & 0.04 \\
\hline
\end{tabular}

Table $7 \quad \mathrm{CO}_{2}$ emissions of supercooling.

\begin{tabular}{|c|c|c|c|c|c|c|}
\hline & \multirow[b]{2}{*}{ Supercooling } & \multicolumn{4}{|c|}{ Amount of $\mathrm{CO}_{2}$ emissions $\left(\mathrm{kg}-\mathrm{CO}_{2}\right)$} & \multirow{2}{*}{$\begin{array}{l}\text { Reduction of } \mathrm{CO}_{2} \text { emission } \\
(\mathrm{kg})\end{array}$} \\
\hline & & $\begin{array}{l}\text { Refrigerated } \\
\text { cabinet }\end{array}$ & $\begin{array}{l}\text { Refrigeration } \\
\text { apparatus }\end{array}$ & Pump & Sum total & \\
\hline \multirow{2}{*}{ Summer } & - & 31.1 & - & - & 31.1 & - \\
\hline & ० & 23.0 & 7.3 & 1.0 & 31.4 & -0.3 \\
\hline \multirow{2}{*}{$\begin{array}{l}\text { Intermediate } \\
\text { season }\end{array}$} & - & 18.5 & - & - & 18.5 & - \\
\hline & $\circ$ & 15.6 & 7.3 & 1.0 & 23.9 & -5.4 \\
\hline \multirow{2}{*}{ Winter } & - & 16.1 & - & - & 16.1 & - \\
\hline & o & 15.0 & 7.3 & 1.0 & 21.7 & -7.2 \\
\hline
\end{tabular}

Table 8 Comparison of $\mathrm{CO}_{2}$ emission with or without exhaust heat.

\begin{tabular}{|c|c|c|c|c|c|c|c|c|}
\hline \multirow[b]{2}{*}{ Operation method } & \multicolumn{7}{|c|}{ Amount of $\mathrm{CO}_{2}$ emissions $\left(\mathrm{kg}-\mathrm{CO}_{2}\right)$} & \multirow{2}{*}{$\begin{array}{l}\text { Reduction of } \\
\mathrm{CO}_{2} \text { emission } \\
(\mathrm{kg})\end{array}$} \\
\hline & $\begin{array}{l}\text { Super } \\
\text { cooling }\end{array}$ & $\begin{array}{l}\text { Refrigerated } \\
\text { cabinet }\end{array}$ & $\begin{array}{l}\text { Adsorption } \\
\text { refrigerator }\end{array}$ & Pump & $\begin{array}{l}\text { HP air } \\
\text { conditioner }\end{array}$ & $\begin{array}{l}\text { Fan coil } \\
\text { unit }\end{array}$ & Sum total & \\
\hline $\begin{array}{l}\text { Without exhaust } \\
\text { Heat }\end{array}$ & - & 31.1 & - & - & 13.6 & - & 44.7 & - \\
\hline $\begin{array}{l}\text { With } \\
\text { exhaust heat }\end{array}$ & 0 & 23.0 & 7.3 & 1.0 & - & 0.5 & 31.8 & 12.9 \\
\hline
\end{tabular}

Table $9 \mathrm{CO}_{2}$ reduction effect of desiccant system.

\begin{tabular}{llllllll}
\hline & \multicolumn{3}{c}{ Amount of $\mathrm{CO}_{2}$ Emissions $\left(\mathrm{kg}-\mathrm{CO}_{2}\right)$} & \multicolumn{2}{c}{ Reduction of } \\
\cline { 2 - 8 } & $\begin{array}{l}\text { Refrigerated } \\
\text { cabinet }\end{array}$ & $\begin{array}{l}\text { Adsorption } \\
\text { refrigerator }\end{array}$ & Pump & $\begin{array}{l}\mathrm{HP} \text { air } \\
\text { conditioner }\end{array}$ & $\begin{array}{l}\text { Desiccant air } \\
\text { conditioner }\end{array}$ & Sum total & $\begin{array}{l}\mathrm{CO}_{2} \\
\text { emission(kg) }\end{array}$ \\
\hline $\begin{array}{l}\text { HP air conditioner } \\
\begin{array}{l}\text { Desiccant air } \\
\text { conditioner }\end{array}\end{array}$ & 31.1 & - & - & 13.6 & - & 44.6 & - \\
\hline
\end{tabular}

which is worth about third part of all. We found that using supercooling and fan coil unit at the same time could lead to reduce large percent of $\mathrm{CO}_{2}$ emissions as a whole. Finally, we examined the variation of $\mathrm{CO}_{2}$ emissions by dehumidification using desiccant air conditioner. The following is the amount of $\mathrm{CO}_{2}$ emissions when we used desiccant air conditioner discussed in Section 3.3.

Table 9 shows that using desiccant air conditioner decreases $\mathrm{CO}_{2}$ emissions. It was found that, we could 


\section{Energy Conservation Effect of Refrigerated Cabinets at Supermarket}

Utilizing the Exhaust Heat from Dispersed Power

decrease the $\mathrm{CO}_{2}$ emissions without supercooling. Therefore, we can expect the additional energy saving benefits by combining supercooling and desiccant air conditioner.

\section{Conclusions}

This study was carried out to validate the effect of energy conservation and carbon dioxide emission reduction by using supercooling and desiccant system at supermarket. Especially, we focused on utilization of exhaust heat from dispersed power and confirmed the effective usage.

The main results are divided into four points shown below:

(1) The outside temperature and inside absolute humidity had influence on the power consumption of the refrigerated cabinet in scale model store;

(2) When the outside air temperature was higher than $14{ }^{\circ} \mathrm{C}$, the power consumption of refrigerated cabinet should be decreased by supercooling;

(3) The dehumidification using desiccant was effective for energy conservation in the high humidity season such as from May to August;

(4) It was difficult to reduce $\mathrm{CO}_{2}$ emission only by supercooling. But combining with other exhaust utilization apparatus, which enabled reduce $30 \%$ of $\mathrm{CO}_{2}$ emission in summertime.

\section{Acknowledgments}

This research is supported financially by the ministry of environment, Government of Japan.

\section{References}

[1] Kadoguchi, K. 2013. "Waste Thermal Energy-Status Quo and Perspective." Energy and Resources 6 (34): 12-6.

[2] Katsuta, M. 2014. "Recent Development in Heat Pump Technology in Japan.” Presented at the 11th International Energy Agency Heat Pump Conference 2014, Montreal, Canada.

[3] Himei, H. 2011. "The Present Conditions Investigation into Power Saving Measures in the Supermarket and Description of the Power Saving Technique of Refrigeration Facilities." In Proceedings of Spatial Economics Research Centre Discussion Paper, Tokyo, 5-20.

[4] NEDO (New Energy and Industrial Technology Development Organization). 2014. Renewable Energy White Paper. Kanagawa: Morikita Publishing Co., Ltd.

[5] Hamamoto, R. 2014. "Energy Conservation of Commercial Refrigerated Cabinets in Supermarkets-Focusing on the Influence of Sub Cooling after Condenser of Cabinets." Presented at the 11th IEA Heat Pump Conference 2014, Montreal, Canada.

[6] Takahashi, H., and Morita, T. 2000. "Showcase and Surrounding Equipment." Refrigeration 75 (876): 852-7.

[7] Yasumatsu, N., and Nagata, K. 2011. "Reduction of Load of Ventilation by Low-Temperature Regeneration Desiccant and Total Heat Exchanger." Refrigeration 86 (1008): 769-73.

[8] Ito, Y. 2012. "Technology and Application of the Room Air Conditioner." Refrigeration 87 (1014): 16-20. 